\title{
REVIEW
}

\section{Drug-Drug Interactions Among Hepatitis C Virus (HCV) and Human Immunodeficiency Virus (HIV) Medications}

\author{
Kirpal Kaur · Mona A. Gandhi · Judianne Slish
}

To view enhanced content go to www.infectiousdiseases-open.com Received: February 11, 2015 / Published online: April 21, 2015

(C) The Author(s) 2015. This article is published with open access at Springerlink.com

\section{ABSTRACT}

One-fourth of individuals diagnosed with the human immunodeficiency virus concomitantly have the hepatitis $C$ virus infection. Since the discovery of highly active antiretroviral therapy, liver complications have become the leading cause of morbidity and mortality in HIV-HCV coinfected individuals. Optimal treatment in this patient population is critical, as coinfection has been linked to deterioration of both disease states. The objective of this review article is to highlight the current literature on drug-drug interactions between HIV and HCV treatments. The management of the treatment of coinfection patients has been covered extensively in numerous other publications.

Keywords: HIV; HCV; HIV-HCV drug interactions

K. Kaur · M. A. Gandhi $(\bowtie) \cdot J$. Slish

St John Fisher College Wegmans School of

Pharmacy, Rochester, NY, USA

e-mail: mgandhi@sjfc.edu

\section{Abbreviations}

$\mathrm{ABC}$

ART

ARV

$\mathrm{ATV} / \mathrm{r}$

AUC

BCRP

BOC

COBI

CYP

DAA

DAV

$\mathrm{DRV} / \mathrm{r}$

DLV

DDI

EFV

ETR

EVG

$\mathrm{FPV} / \mathrm{r}$

FTC

FTC

HAART

HIV

LPV

$\mathrm{LPV} / \mathrm{r}$

NVP

OATP1B1/3

$\mathrm{OBV} / \mathrm{PTV} / \mathrm{r}$

PI

PEG-IFN

PLHIV
Abacavir

Antiretroviral therapy

Antiretroviral

Atazanavir boosted with ritonavir Area under the curve

Breast cancer-resistant protein

Boceprevir

Cobicistat

Cytochrome P450

Direct acting agents

Dasabuvir

Darunavir boosted with ritonavir

Delavirdine

Didanosine

Efavirenz

Etravirine

Elvitegravir

Fosamprenavir

Emtricitabine

Emtricitabine

Highly active antiretroviral

therapy

Human immunodeficiency virus

Lepipasvir

Lopinavir boosted with ritonavir Nevirapine

Organic anion transporter polypeptide

Ombitasvir/paritaprevir/ritonavir

Protease inhibitor

Peginterferon

Persons living with HIV 


$\begin{array}{ll}\text { RAL } & \text { Raltegravir } \\ \text { RBV } & \text { Ribavirin } \\ \text { RPV } & \text { Rilipivirine } \\ \text { RTV } & \text { Ritonavir } \\ \text { SIM } & \text { Simeprevir } \\ \text { SOF } & \text { Sofosbuvir } \\ \text { D4T } & \text { Stavudine } \\ \text { SVR } & \text { Sustained virological response } \\ \text { 3TC } & \text { Lamivudine } \\ \text { TDF } & \text { Tenofovir } \\ \text { TEL } & \text { Telaprevir } \\ \text { UGT1A1 } & \text { UDP-glucuronosyltransferase } \\ & \text { enzyme } \\ \text { ZVD } & \text { Zidovudine }\end{array}$

\section{INTRODUCTION}

Hepatitis C virus (HCV) has emerged as one of the major worldwide health problems with an estimated 130-170 million people being infected [1]. Patients with HCV are accompanied by chronic liver disease, which can lead to fibrosis, cirrhosis, and an increased risk of complications including ascites and hepatocellular carcinoma. Prior to 2014, the gold-standard treatment for HCV genotype 1 was a combination of pegylated interferon (PEG-IFN), including interferon alfa $2 \mathrm{a}$ or $2 \mathrm{~b}$ and ribavirin (RBV) for a duration of 48 weeks or longer. However, this treatment has many limitations including the low sustained virologic response rate, long duration of treatment, and difficult adverse event profiles.

The landscape for HCV treatment is dynamic and rapidly changing. To date, there are four classes of direct-acting antiviral agents (DAA). These are NS3/4A protease inhibitors, NS5A inhibitors, NS5B RNA-dependent polymerase inhibitors, and non-nucleoside polymerase inhibitors. Each class differs in their genotype coverage, treatment status (e.g., treatmentnaïve, relapsers, nonresponders), and coinfected patient populations.
The development of early DAAs (NS3/4A protease inhibitors; telaprevir, boceprevir) instigated a change deviating away from the previous gold-standard regimen. The two firstgeneration NS3/4A protease inhibitors (PI), telaprevir and boceprevir, were approved in 2011 for the treatment of genotype 1-infected patients in combination with PEG-IFN and RBV [2]. Simeprevir, a second-generation NS3/4A PI, was later approved with the same regimen in patients with compensated liver disease.

Recently, a nucleotide analog, sofosbuvir, received FDA approval for the treatment of $\mathrm{HCV}$ genotypes 1-6. Sofosbuvir has completely changed the basis of the treatment of HCV. For the first time in the history of this disease, a non-interferon-based regimen was approved as first line for the treatment of HCV. Depending on the hepatitis $\mathrm{C}$ genotype, an all-oral regimen was also made possible. A combination product consisting of ledipasvir, aNS5A inhibitor, and sofosbuvir (Harvoni ${ }^{\circledR}$ ) was the first once-daily single tablet regimen to treat chronic hepatitis C genotype 1 and 4 infection in adults. An additional combination product consisting of ombitasvir, an NS5A inhibitor, paritaprevir, an NS3/4A protease inhibitor, dasabuvir, an NS5B palm polymerase inhibitor, and ritonavir, a cytochrome P450 3A inhibitor, was also recently approved.

Highly active antiretroviral therapy (HAART) is the mainstay therapy for HIV. The standard recommended treatments for naive patients with HIV-1 infection usually consist of two nucleoside/nucleotide reverse transcriptase inhibitors, in combination with a nonnucleoside reverse transcriptase inhibitor, a ritonavir-boosted protease inhibitor, or an integrase strand transfer inhibitor [3]. Over recent years, significant advances have been made to therapy with the introduction of fixeddose drug combinations. This allows the 
administration of up to three and more antiretroviral (ARV) drugs in one tablet, providing more convenient once-daily administration such as Atripla ${ }^{\circledR}$, Stribild ${ }^{\circledR}$ etc. [4].

Seven million persons worldwide are infected with both HIV and HCV [5]. HIV/ $\mathrm{HCV}$ coinfection is associated with higher rates of liver fibrosis, cirrhosis, hepatocellular carcinoma, and overall mortality compared to either infection alone [6]. It has been established that coinfected patients who are treated optimally for $\mathrm{HCV}$ have improved clinical outcomes and survival [7]. However, drug interactions among HIV and HCV agents limit the appropriate treatment of either disease state, leading to severe complications and even early deaths in this patient population. This review is designed to summarize the current literature on drug interactions between $\mathrm{HCV}$ and HIV treatment regimens.

\section{METHODS}

Relevant information was identified through a comprehensive literature search (January 2003 to March 2015) in PubMed using the keywords HIV, HCV, HIV/HCV coinfection, nonstructural protein 5B (NS5B) protease inhibitors, and drug interactions for boceprevir, dasabuvir, ledipasvir, ombitasvir, paritaprevir, pegylated interferon, ribavirin, simeprevir, sofosbuvir and telaprevir. Package inserts for these drugs were also reviewed. Abstracts of the articles selected were reviewed, and those satisfying the inclusion criteria (pharmacokinetics and drug interactions of $\mathrm{HCV} / \mathrm{HIV}$ drugs) were included in the analysis. Gilead Sciences, Inc., the manufacturer for Harvoni ${ }^{\circledR}$, was also contacted to confirm its specific drug interactions with HIV medications. This content was included in the review for completeness. This article is based on previously conducted studies and does not involve any new studies of human or animal subjects performed by any of the authors.

\section{RESULTS}

This article reviews drug interactions between established HCV and HIV medications. Drugs pending approval were not included in this review because of lack of available data. Summaries of the drug interactions and their mechanisms are presented in Tables 1 and 2 .

\section{Sofosbuvir (Sovaldi ${ }^{\circledR}$ )}

Sofosbuvir (SOF) is a direct-acting antiviral agent against hepatitis $\mathrm{C}$ virus infection. It is an oral nucleotide analog and inhibits NS5B polymerase, a non-structural protein 5B (NS5B), and an RNA-dependent RNA polymerase responsible for the synthesis of copying of the RNA viral genome [8]. Phase 3 trials of SOF, involving patients with hepatitis $\mathrm{C}$ virus alone, have demonstrated high rates of sustained virological response (SVR) when used in combination with ribavirin for 12 weeks for hepatitis $C$ virus genotype 2, 12-24 weeks for $\mathrm{HCV}$ genotype 3 , and 12 weeks for $\mathrm{HCV}$ genotypes 1, 4, 5, and 6 in combination with PEG-IFN and RBV [9-11]. Upon oral administration, SOF is rapidly converted into the GS-331007 metabolite, which is dominant and accounts for $\geq 90 \%$ drug-related exposure in the body [8]. SOF is responsible only for approximately $4 \%$ drug exposure in the body. It is a substrate of drug transporter p-glycoprotein (P-gp) and breast cancerresistant protein (BCRP) [8]. However, P-gp and BCRP do not affect GS-331007, the 
Table 1 Main drug-drug CYP and P-gp interactions between HCV and HIV medications

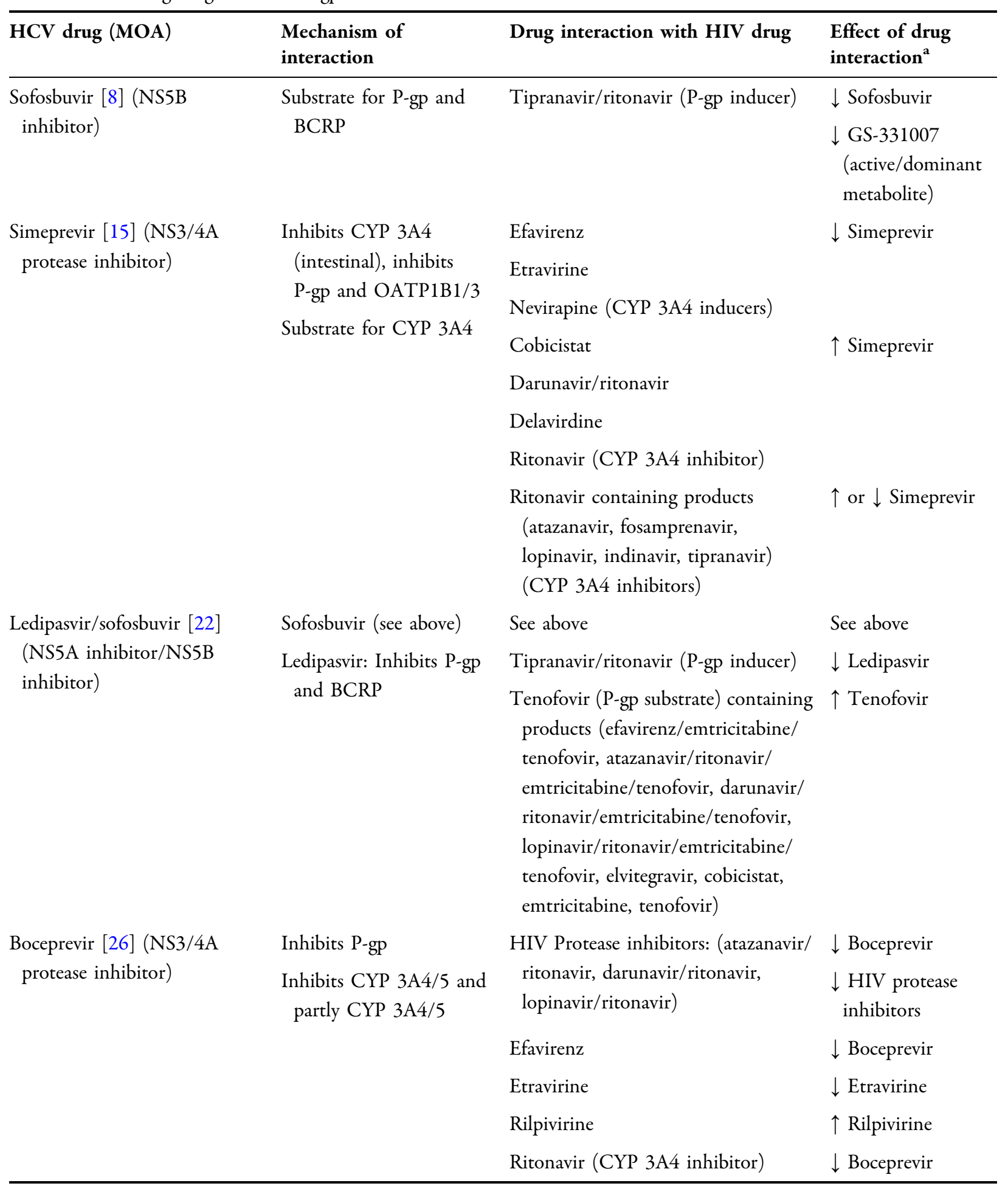


Table 1 continued

\begin{tabular}{|c|c|c|c|}
\hline HCV drug (MOA) & $\begin{array}{l}\text { Mechanism of } \\
\text { interaction }\end{array}$ & Drug interaction with HIV drug & $\begin{array}{l}\text { Effect of drug } \\
\text { interaction }\end{array}$ \\
\hline \multirow[t]{5}{*}{$\begin{array}{l}\text { Telaprevir }[28,31,32](\mathrm{NS} 3 / 4 \mathrm{~A} \\
\text { protease inhibitor })\end{array}$} & $\begin{array}{l}\text { Strongly inhibits CYP } \\
\text { 3A4 }\end{array}$ & Atazanavir/ritonavir & $\begin{array}{l}\downarrow \text { Telaprevir } \\
\uparrow \text { Atazanavir }\end{array}$ \\
\hline & \multirow[t]{4}{*}{ Moderately inhibits P-gp } & Darunavir/ritonavir & $\begin{array}{l}\downarrow \text { Telaprevir } \\
\downarrow \text { Darunavir }\end{array}$ \\
\hline & & Fosamprenavir/ritonavir & $\begin{array}{l}\downarrow \text { Telaprevir } \\
\downarrow \text { Amprenavir }\end{array}$ \\
\hline & & Lopinavir/ritonavir & $\begin{array}{l}\downarrow \text { Telaprevir } \\
\leftrightarrow \text { Lopinavir }\end{array}$ \\
\hline & & Efavirenz & $\begin{array}{l}\downarrow \text { Telaprevir } \\
\downarrow \text { Efavirenz }\end{array}$ \\
\hline \multirow{6}{*}{$\begin{array}{l}\text { Paritaprevir [37] (NS3/4A } \\
\text { protease inhibitor) }\end{array}$} & Inhibitor of UGT1A1 & Atazanavir/ritonavir & $\uparrow$ Paritaprevir \\
\hline & Metabolized CYP 3A & Darunavir/ritonavir & $\downarrow$ Paritaprevir \\
\hline & \multirow{3}{*}{$\begin{array}{l}\text { Inhibitor and substrate of } \\
\text { OATP1B1 and } \\
\text { OATP1B3 }\end{array}$} & Darunavir & $\uparrow$ Paritaprevir \\
\hline & & Lopinavir/ritonavir & $\uparrow$ Paritaprevir \\
\hline & & \multirow[t]{2}{*}{ Rilpivirine } & \multirow[t]{2}{*}{$\uparrow$ Paritaprevir } \\
\hline & Substrate P-gp, BCRP & & \\
\hline \multirow{5}{*}{$\begin{array}{l}\text { Ombitasvir [37] (NS5A } \\
\text { inhibitor) }\end{array}$} & Inhibitor of UGT1A1 & Atazanavir/ritonavir & $\downarrow$ Ombitasvir \\
\hline & \multirow{4}{*}{$\begin{array}{l}\text { Metabolized via amide } \\
\text { hydrolysis CYP plays } \\
\text { minor role } \\
\text { Substrate P-gp and BCRP }\end{array}$} & Darunavir/ritonavir & $\downarrow$ Ombitasvir \\
\hline & & Darunavir & $\downarrow$ Ombitasvir \\
\hline & & Lopinavir/ritonavir & $\downarrow \uparrow$ Ombitasvir \\
\hline & & Rilpivirine & $\uparrow$ Ombitasvir \\
\hline \multirow{5}{*}{$\begin{array}{l}\text { Dasabuvir [37] (non-nucleoside } \\
\text { NS5B palm polymerase } \\
\text { inhibitor) }\end{array}$} & Inhibitor UGT1A1 & Atazanavir/ritonavir & $\downarrow$ Dasabuvir \\
\hline & Inhibitor BCRP & Darunavir/ritonavir & $\downarrow$ Dasabuvir \\
\hline & Metabolized by CYP 2C8 & Darunavir & $\downarrow$ Dasabuvir \\
\hline & \multirow[t]{2}{*}{ Substrate P-gp and BCRP } & Lopinavir/ritonavir & $\downarrow$ Dasabuvir \\
\hline & & Rilpivirine & $\uparrow$ Dasabuvir \\
\hline
\end{tabular}

Drug interaction for ribavirin and peginterferon was not included in this table because of different drug-interaction mechanisms

a The direction of the arrow ( $\uparrow=$ increase, $\downarrow=$ decrease, $\leftrightarrow=$ no change) indicates the direction of the change in drug concentration 
Table 2 Drug-drug interactions for HIV medications when coadministered with Viekira Pak $^{\mathrm{TM}}$ [37]

\begin{tabular}{lll}
\hline HCV DAA & Drug interaction with HIV drug & Effect of drug interaction AUC \\
\hline OBV $/$ PTV $/ r+$ DAV & Atazanavir/ritonivr & $\uparrow$ Atazanavir \\
$\mathrm{OBV} / \mathrm{PTV} / \mathrm{r}+\mathrm{DAV}$ & Darunavir & $\uparrow$ or $\downarrow$ Darunavir \\
$\mathrm{OBV} / \mathrm{PTV} / \mathrm{r}+\mathrm{DAV}$ & Darunavir/ritonavir & $\downarrow$ Darunavir \\
$\mathrm{OBV} / \mathrm{PTV} / \mathrm{r}+\mathrm{DAV}$ & Lopinavir/ritonavir & $\downarrow$ Lopinavir \\
$\mathrm{OBV} / \mathrm{PTV} / \mathrm{r}+\mathrm{DAV}$ & Rilpivirine & $\uparrow$ Rilpivirine \\
\hline
\end{tabular}

a Dependent on dosing regimen

dominant metabolite [8]. Agents that induce P-gp in the intestine (e.g., rifampin) may decrease SOF plasma concentrations, reducing the therapeutic efficacy of SOF and thereby increasing the patient's risk of $\mathrm{HCV}$ exacerbations [8]. On the other hand, coadministration of SOF with drugs that inhibit P-gp (e.g., quinidine) and/or BCRP (e.g., elacridar) may increase the SOF plasma concentration without increasing the GS331007 plasma concentration [8]. Accordingly, SOF may be coadministered with P-gp and/or BCRP inhibitors.

\section{Sofosbuvir Drug-Drug Interactions with HIV Medications}

Tipranavir (TPV) is a PI that is indicated for treatment of resistant HIV genotype-1 infected patients in combination with other antiretroviral agents [12]. TPV is a P-gp inhibitor and therefore may increase the plasma concentration of SOF, a P-gp substrate. No studies were found to support this drug interaction; however, the American Association for the Study of Liver Diseases (AASLD) guidelines recommends avoiding the use of SOF if the patient is concomitantly taking TPV [13]. The hepatic cytochrome (CYP) P450 enzyme complex does not metabolize SOF [8]. A drug interaction study with efavirenz (EFV), tenofovir (TDF), emtricitabine (FTC), rilpivirine (RPV), darunavir/ritonavir (DRV/r), and raltegravir (RAL) in noninfected individuals identified no clinically significant interactions [14]. Since no interactions with cytochrome $\mathrm{P} 450$ enzymes were identified, SOF is an ideal option for patients with HIV/HCV coinfection.

\section{Simeprevir $\left(\right.$ Olysio $\left.^{\circledR}\right)$}

Compared to other protease inhibitor medications, simeprevir (SIM) is a relatively small macrocyclic drug that targets and selectively inhibits $\mathrm{HCV}$ NS3/4A serine protease, thereby blocking the enzyme that enables HCV to replicate in host cells [15]. It is FDA approved for the treatment of genotype 1 chronic hepatitis $\mathrm{C}$ in combination with PEGIFN and RBV. SIM is a competitive, reversible, macrocyclic, noncovalent inhibitor that has improved affinity and selectivity for protein targets when compared to telaprevir (TEL) and BOC $[15,16]$. SIM is a weak inhibitor of CYP 1A2 activity and intestinal CYP 3A4 activity, but does not affect hepatic CYP 3A4 activity. Furthermore, SIM inhibits OATP1B1/3 and P-gp transporters. Coadministration of SIM with drugs that are substrates for CYP 3A4 (e.g., amiodarone), OATP1B1/3 (e.g., methotrexate) and P-gp (e.g., digoxin) transport may result in increased plasma concentrations of such drugs. In addition, SIM is also a substrate for CYP 3A4 and can therefore be the subject of drug-drug interactions with moderate or strong inhibitors 
(e.g., erythromycin) and inducers (e.g., phenytoin) of CYP 3A4 enzyme, with significant increases or decreases in exposure to SIM [15].

\section{Simeprevir Drug-Drug Interactions with HIV Medications}

EFV is a non-nucleoside reverse transcriptase inhibitor (NNRT) and a strong inducer of CYP 3A4 enzyme [17]. Use of SIM with EFV significantly decreased plasma concentrations of SIM and therefore their concomitant use is not recommended [15].

Cobicistat (COBI) is a pharmacokinetics enhancer with no activity against HIV and is used with ATZ, DRV, and in a fixed dose combination of Stribild ${ }^{\circledR} \quad$ (elvitegravir/ cobicistat/tenofovir/emtricitabine) $\quad[18,19]$. COBI strongly inhibits CYP 3A4 and may increase SIM plasma concentrations [18]. Use of SIM with COBI (including COBI-containing products) is not recommended.

Furthermore, coadministration of SIM and $\mathrm{DRV} / \mathrm{r}$ is not recommended because of the significant increase in SIM exposure (AUC: $\uparrow$ 159\%' $\left.C_{\max }: \uparrow 79 \% ; C_{\min }: \uparrow 358 \%\right)$ in the presence of $\mathrm{DRV} / \mathrm{r}$, even after dose adjustment of SIM $[15,20]$, resulting in their exclusion from the phase $3 \mathrm{C} 212$ clinical trial assessing simeprevir in combination with PEG-IFN and RBV in patients with HIV/HCV coinfection.

Concomitant use of SIM with ritonavir (RTV) including RTV-containing combinations with delavirdine (DLV), etravirine (ETR), or nevirapine (NVP) may result in altered plasma concentrations of SIM because of CYP 3A4 inhibition (DLV/r) or induction (ETR and NVP) by these drugs. Coadministration of SIM with DLV, ETR, NVP, and RTV is not recommended [15].

The SIM drug interaction study by Ouwerkerk-Mahadevan et al. [21] found no substantial interactions with TDF, RPV, and RAL.

\section{Ledipasvir/Sofosbuvir (Harvoni ${ }^{\circledR}$ )}

The recently approved Harvoni ${ }^{\circledR}$ is a fixed dose combination of ledipasvir (LDV), an HCV NS5A inhibitor, and sofosbuvir (SOF), an HCV nucleotide analog NS5B polymerase inhibitor [22]. LDV/SOF has been indicated for the treatment of chronic hepatitis $\mathrm{C}$ genotype 1 infection in adults [22]. Efficacy and safety have been demonstrated in three phase 3 clinical trials of LDV/SOF administered with or without RBV [23, 24].

\section{Ledipasvir/Sofosbuvir Drug-Drug Interactions with HIV Medications}

The drug interactions with SOF as discussed previously apply to this combination as well. LDV is an inhibitor of the drug transporters P-gp and BCRP and has the potential to increase intestinal absorption of coadministered substrates for these transporters [22]. Two phase 1, open-label, multiple-dose crossover PK studies were conducted to evaluate drugdrug interactions between LDV or LDV/SOF and common HIV antiretroviral agents in healthy subjects [25]. LDV or LDV/SOF pharmacokinetics were unaffected by RAL or a combination of FTC, RPV, and TDF with brand name Complera ${ }^{\circledR}$. Small $(<20 \%)$ changes in RAL PK were observed with coadministration of LDV [25]. A modest $(\sim 34 \%)$ decrease in LDV exposure was observed with no impact on SOF PK when coadministered with EFV/FTC/TDF $\left(\right.$ Atripla $\left.{ }^{\circledR}\right)$. However, these changes were not deemed clinically relevant in the study. Increased TDF exposure was observed when LDV/SOF was coadministered with EFV/FTC/ TDF (1.98-fold) and FTC/RPV/TDF (1.4-fold) $[22,25]$. It is recommended to consider 
alternative HCV or ARV therapy to avoid an increase in TDF exposures. If coadministration is necessary, monitor for TDF-associated adverse reactions in patients receiving $\mathrm{LDV} / \mathrm{SOF}$ and TDF-boosted ARV regimens.

A drug-drug interaction study evaluating LDV/SOF with Stribild ${ }^{\circledR}$ (EVG/COBI/FTC/TDF) has not been conducted; however, based on its coadministration with RTV-boosted HIV protease inhibitors, LDV/SOF with EVG/COBI/ FTC/TDF is expected to increase TDF concentrations. The safety of increased TDF concentrations when used in combination with LDV/SOF and EVG/COBI/FTC/TDF has not been established. Coadministration of EVG/COBI/ FTC/TDF with LDV/SOF is not recommended [22].

Coadministration of LDV/SOF with TPV with RTV is expected to decrease the concentration of LDV and SOF, leading to a reduced therapeutic effect of LDV/SOF. According to prescribing information, coadministration of LDV/SOF with TPV/RTV is not recommended [22].

According to the package insert, no clinical drug interactions have been observed or are expected when LDV/SOF is used with abacavir (ABC), ATV/r, DRV/r, EFV, FTC, lamivudine (3TC), RAL, RPV, or TDF antiretroviral agents [22].

\section{Boceprevir (Victrelis ${ }^{\circledR}$ )}

Boceprevir (BOC) is a hepatitis C virus NS3/4A protease inhibitor and is indicated for the treatment of chronic hepatitis $\mathrm{C}$ genotype 1 infection in adults in combination with PEGIFN and RBV [26]. This medication is no longer recommended for coinfected individuals because of the lower efficacy rates, longer treatment duration, substantial drug interactions, and enhanced adverse effect profile in comparison to other treatment alternatives.

\section{Boceprevir Drug-Drug Interactions with HIV Medications}

BOC is primarily metabolized by aldoketoreductase, and this enzyme does not affect any HIV medication. However, BOC is a strong inhibitor of CYP 3A4/5 and partly metabolized by CYP 3A4/5 [26]. Drugs metabolized primarily by CYP 3A4/5 may have increased exposure when administered with BOC, which may increase or prolong their therapeutic and adverse effects. In addition, BOC is a potential inhibitor of P-gp based on in vitro studies [26]. A randomized, open-label study assessed the pharmacokinetic interactions between BOC and RTV-boosted PIs (PI/r), ATV/r, lopinavir (LPV/r), or DRV, each with RTV, and concluded that concomitant administration of BOC with $\mathrm{PI} / \mathrm{r}$ reduced exposures of the HIV protease inhibitors, RTV, and BOC [27]. This study raises no toxicity-related safety concerns, but concluded that the drug-drug interactions may potentially reduce the effectiveness of these HIV therapies and/or BOC [27]. According to the prescribing information, plasma trough concentrations of BOC were decreased when coadministered with EFV, a strong inducer of CYP 3A4, and resulted in loss of therapeutic effect. Therefore, it is not recommended to use these two agents together [26].

\section{Telaprevir (Incivek $^{\circledR}$ )}

Telaprevir (TEL) is a direct-acting antiviral agent against the hepatitis $\mathrm{C}$ virus and inhibits $\mathrm{HCV}$ $\mathrm{NS} 3 / 4 \mathrm{~A}$ protease, which is essential for viral replication [28]. TEL is FDA approved for the treatment of genotype 1 chronic hepatitis $\mathrm{C}$ in adult patients in combination with PEG-IFN and RBV. It is no longer recommended for 
coinfected individuals because of the lower efficacy rates, longer treatment duration, substantial drug interactions, and adverse effect profile in comparison to other available treatments.

\section{Telaprevir Drug-Drug Interactions with HIV Medications}

TEL is a strong inhibitor of CYP $3 \mathrm{~A} 4$ and a moderate inhibitor of P-gp. Coadministration of TEL with agents that are primarily metabolized by CYP 3A4 (e.g., lovastatin) and/or substrates for P-gp (e.g., digoxin) transport may result in increased plasma concentrations of such drugs, which could increase or prolong their therapeutic effect and adverse reactions. A pharmacokinetic study examined the interaction between TEL and EFV (a known inducer of CYP 3A4), showing that steady-state EFV decreased the AUC ( 26\%) and Cmin ( $\sim 47 \%)$ of telaprevir, whereas TEL had no significant effects on the PK of EFV [29]. In another study, TEL increased the exposure of RPV ( 1.8-fold) and decreased the exposures of $\mathrm{DRV} / \mathrm{r} \quad(\sim 40 \%)$ and fosamprenavir/ritonavir (FPV/r; $\sim 47 \%$ ) [30]. TEL had no effect on RAL, $\mathrm{ATV} / \mathrm{r}, \mathrm{LPV} / \mathrm{r}$, and/or ETR exposures [31, 32]. On the other hand, RAL, RPV, ETR, and ATV/r $(\sim 35 \%)$, and LPV/r $\quad(\sim 54 \%)$ significantly reduced the AUC of TEL $[31,32]$. The prescribing information for TEL does not recommend its use with DRV/r, FPV/r, and LPV/ $\mathrm{r}$ [28]. In addition, according to the prescribing information, coadministration of TEL and TDF led to an increase in TDF exposure. Increased clinical and laboratory monitoring is warranted in this patient population.

\section{Ribavirin (Rebetol ${ }^{\circledR}$ )}

Ribavirin (RBV) is a nucleoside analog with antiviral activity and is indicated for the treatment of chronic hepatitis $\mathrm{C}$ virus infection in combination with pegylated interferon alfa $2 \mathrm{a}$ or $2 \mathrm{~b}$ (PEG-IFN) in chronic hepatitis $\mathrm{C}$ patients [33].

\section{Ribavirin Drug-Drug Interactions with HIV Medications}

In vitro studies indicated that RBV does not inhibit CYP 2C9, CYP 2C19, CYP 2D6, or CYP $3 \mathrm{~A} 4$, with the least potential for drug interactions. However, in vitro data results show that RBV reduces phosphorylation of 3TC, stavudine (D4T), and zidovudine (ZVD) [33]. Coadministration of RBV and didanosine (DDI) is contraindicated because of an increased risk of adverse events, in particular of mitochondrial toxicity [33]. Based on in vitro data, RBV increases the intracellular triphosphate levels of DDI. However, in another study, pharmacokinetic interactions were not found between DDI and RBV [34]. In study NR15961, patients who were administered ZVD in combination with PEGIFN developed severe neutropenia and anemia more frequently than similar patients not receiving ZVD (neutropenia $15 \%$ vs. 9\%) (anemia 5\% vs. 1\%) [35]. According to the prescribing information, it is recommended to discontinue ZVD as medically necessary.

\section{Pegylated Interferon}

(Pegasys $^{\circledR}$, PEG-Intron ${ }^{\circledR}$ )

Two pegylated interferon (PEG-IFN $\alpha 2 \mathrm{a} / 2 \mathrm{~b}$ ) molecules are commercially available for the treatment of chronic hepatitis $C$. These differ in the size and nature of the covalently attached polyethylene glycol (PEG) moiety, with resulting differences in pharmacokinetics and dosing regimens [36]; however, these variations do not affect the overall drug interaction profile. It is no longer recommended for coinfected individuals because of the lower 
efficacy rates, longer treatment duration, substantial drug interactions, and adverse effect profile in comparison to other available treatments.

\section{PEG-IFN Drug-Drug Interactions with HIV Medications}

Therapy with PEG-IFN commonly includes combination therapy with ribavirin. Hence, the drug interactions described for ribavirin also apply to the combination of pegylated interferon and ribavirin. No drug-drug interactions were found between PEG-IFN and ARV therapy.

\section{Paritaprevir/Ritonavir/Ombitasvir Plus Dasabuvir (Viekira Pak ${ }^{\mathrm{TM}}$ )}

The recently approved Viekira Pak ${ }^{\mathrm{TM}}$ includes a combination of ombitasvir (OBV), a hepatitis $\mathrm{C}$ NS5A inhibitor, paritaprevir (PTV), a hepatitis C NS3/4A protease inhibitor, ritonavir ( $\mathrm{r}$ ), a CYP $3 \mathrm{~A}$ inhibitor, and dasabuvir (DAV), a hepatitis $\mathrm{C}$ non-nucleoside NS5B palm polymerase inhibitor [37]. OBV/PTV/r + DAV has been indicated for the treatment of chronic hepatitis $\mathrm{C}$ genotype 1 infection including those with compensated cirrhosis. Six phase 3 clinical trials have evaluated the safety and efficacy of OBV/PTV/r + DAV with or without RBV in subjects with chronic hepatitis C genotype 1 [37-42]. One additional trail incorporated individuals with $\mathrm{HIV} / \mathrm{HCV}$ coinfection [43].

OBV, PTV, and DAV are all inhibitors of UGT1A1, and RTV is an inhibitor of CYP450 3/A4. PTV is an inhibitor of OATP1B1 and 1B3, while PTV, RTV, and DAV are inhibitors of BCRP. Drugs that are substrates may result in increased plasma concentrations of the drugs when coadministered with OBV/PTV/r + DAV [37]. There is also a potential for other drugs to alter the effect(s) of one or more of the components of Viekira $\mathrm{Pak}^{\mathrm{TM}}$. PTV and RTV are mainly metabolized by CYP $3 \mathrm{~A}$ enzymes and DAV by CYP 2C8 enzymes. Concomitant use of medications that are inhibitors and/or inducers of the above enzymes may increase or decrease the plasma concentrations of these agents. OBV is primarily metabolized by amide hydrolysis with only a minor metabolism by CYP enzymes. OBV, PTV, DAV, and RTV are all substrates of P-gp. OBV, PTV, and DAV are substrates of BCRP. PTV is a substrate of OATP1B1 and 1B3. Many complex drug-drug interactions have the potential to occur while utilizing OBV/PTV/ $r+$ DAV. Summaries of the drug interactions between ARV and DAA are presented in Tables 1 and 2.

\section{Viekira Pak ${ }^{T M}(P T V / r, O B V$, and DAV) and Drug-Drug Interactions with HIV Medications}

It is recommended to use OBV/PTV/r and DAV in combination with antiretrovirals that do not have substantial interactions such as raltegravir (possibly dolutegravir) enfuvirtide, tenofovir, emtricitabine, lamivudine, and atazanavir when possible. If a protease inhibitor is utilized, it should be given at the same time as the fixed-dose regimen, and adjustment of the RTV dose should be considered during the HCV treatment since the OBV/PTV/r + DAV contains RTV as a booster. PTV is metabolized by cytochrome P450 3A4 (CYP 3A4), and requires ritonavir boosting to achieve serum levels that are adequate to treat $\mathrm{HCV}$. Since ritonavir has anti-HIV activity, HIV/HCV-coinfected patients should have achieved HIV RNA suppression prior to initiation of OBV/PTV/r + DAV. Uses of this fixed-dose combination should be avoided because of the potential for low-dose RTV to select for HIV protease inhibitor resistance in coinfected patients not recieiving antiretroviral 
therapy. It is not recommended to utilize the $\mathrm{OBV} / \mathrm{PTV} / \mathrm{r}+\mathrm{DAV}$ combination with efavirenz, rilpivirine, darunavir, or lopinavir/ $\mathrm{r}$ combinations [13].

When OBV/PTV $/ \mathrm{r}+\mathrm{DAV}$ combination therapy was combined with efavirenz, emtricitabine, and tenofovir, clinically significant gastrointestinal and neurologic adverse events occurred, with elevations of alanine aminotransferase levels, thus presenting a contraindication to coadministration with efavirenz. When the entire regimen was combined with rilpivirine, exposure to rilpivirine was substantially increased. Higher concentrations of rilpivirine has the potential to prolong the QT interval; therefore, rilpivirine should not be used with paritaprevir/ritonavir/ ombitasvir plus dasabuvir and RBV. Noninfected volunteer studies did not reveal significant interactions with tenofovir/ emtricitabine or raltegravir that warranted any dose adjustments or concern for excess toxicity when utilized together [37]. Since PTV is an inhibitor of the OATP1B1 bilirubin transporter, it may increase indirect bilirubin, especially while taking atazanavir (ATV) as part of the ARV regimen [44].

PTV has been studied as part of the entire regimen with boosted HIV protease inhibitors atazanavir, darunavir, and lopinavir in noninfected individuals. There were minimal changes to the maximum concentration $\left(C_{\max }\right)$ and AUC for these antiretroviral drugs, although trough concentrations were increased for atazanavir and lopinavir and decreased for darunavir. Although paritaprevir $C_{\max }$ and AUC values were minimally to moderately increased, no dose adjustment has been recommended [45]. Because $100 \mathrm{mg}$ of ritonavir is coformulated with paritaprevir and ombitasvir, the total dose of ritonavir must be carefully considered when using ritonavir- containing antiretroviral regimens. Coadministration with ritonavir-boosted lopinavir would result in $300 \mathrm{mg}$ daily of ritonavir. This dose has been associated with adverse gastrointestinal effects; as a result, this combination is not recommended.

In noninfected volunteers, when OBV/PTV/ $\mathrm{r}+\mathrm{DAV}$ was combined with efavirenz, emtricitabine, and tenofovir, clinically significant gastrointestinal and neurologic adverse events occurred [46]. Elevations of alanine aminotransferase levels occurred when administered with efavirenz; therefore, coadministration with efavirenz is not recommended [46]. When the entire regimen was combined with rilpivirine, exposures to rilpivirine were substantially increased [46]. A higher concentration of rilpivirine has the potential to prolong the QT interval; therefore, rilpivirine should not be used with OBV/PTV/r plus DAV and RBV.

Twenty-eight HIV/HCV-coinfected subjects already taking ritonavir-boosted atazanavir (ritonavir coming from the $\mathrm{HCV}$ regimen during the time of coadministration) were treated with an OBV/PTV/r + DAV and RBV regimen as part of the TURQUOISE-1 study and 35 patients receiving tenofovir/ emtricitabine with raltegravir [43]. Patients tolerated the combinations well without requiring discontinuation for treatment-related serious adverse effects or medication intolerance.

\section{CONCLUSION}

Coinfection with HIV and HCV is a serious problem resulting in many complications including faster liver decompensation, cirrhosis, and hepatic carcinoma. Optimal treatment is necessary to avoid such complications. It is very important to address 
drug-drug interactions between these two regimens to avoid adverse effects and a decrease in efficacy, thereby increasing adherence to therapy. Post-marketing data will be helpful to evaluate and quantify additional drug interactions/intolerances between HIV and HCV drugs.

\section{ACKNOWLEDGMENTS}

No funding or sponsorship was received for this study or publication of this article. All named authors meet the International Committee of Medical Journal Editors (ICMJE) criteria for authorship for this manuscript, take responsibility for the integrity of the work as a whole, and have given final approval for the version to be published.

Conflict of interest. Kirpal Kaur, Mona A. Gandhi, and Judianne Slish declare no conflict of interest.

Compliance with ethics guidelines. This article is based on previously conducted studies and does not involve any new studies of human or animal subjects performed by any of the authors.

Open Access. This article is distributed under the terms of the Creative Commons Attribution Noncommercial License which permits any noncommercial use, distribution, and reproduction in any medium, provided the original author(s) and the source are credited.

\section{REFERENCES}

1. Centers for Disease Control and Prevention; Infectious diseases related to travel http://wwwnc. cdc.gov/travel/yellowbook/2014/chapter-3-infectious -diseases-related-to-travel/hepatitis-c. Accessed Dec 2, 2014.

2. Puotia M, Rossottia R, Travia G, et al. Optimizing treatment in HIV/HCV co-infection. Dig Liver Dis. 2013;45S:S355-62.

3. Panel on Antiretroviral Guidelines for Adults and Adolescents. Guidelines for the use of antiretroviral agents in HIV-1-infected adults and adolescents. Department of Health and Human Services. http:// aidsinfo.nih.gov/contentfiles/lvguidelines/adultand adolescentgl.pdf. Accessed Dec 3, 2014.

4. Deeks ED, Perry CM. Efavirenz/emtricitabine/ tenofovir disoproxil fumarate single-tablet regimen (Atripla RM): a review of its use in the management of HIV infection. Drugs. 2010;70(17): 2315-38.

5. Soriano V, Vispo E, Labarga $P$, et al. Viral hepatitis and HIV co-infection. Antivir Res. 2010;85(1):303-15.

6. Weber R, Sabin CA, Friis-Miller N, et al. Liverrelated deaths in persons infected with the human immunodeficiency virus: the D:A: D study. Arch Intern Med. 2006;166(15):1632-41.

7. Limketkai BN, Mehta SH, Sutcliffe CG, et al. Relationship of liver disease stage and antiviral therapy with liver-related events and death in adults co-infected with HIV/HCV. JAMA. 2012;308(4):370-8.

8. Sovaldi ${ }^{\circledR}$ (package insert). Gilead Sciences, Inc.; Foster City, CA; 2014.

9. Lawitz E, Mangia A, Wyles D, et al. Sofosbuvir for previously untreated chronic hepatitis $\mathrm{C}$ infection. N Engl J Med. 2013;368:1878-87.

10. Kowdley KV, Lawitz E, Crespo I, et al. Sofosbuvir with pegylated interferon alfa-2a and ribavirin for treatment-naive patients with hepatitis $\mathrm{C}$ genotype-1 infection (ATOMIC): an open-label, randomized, multicentre phase 2 trial. Lancet. 2013;381:2100-7.

11. Jacobson IM, Gordon SC, Kowdley KV, et al. Sofosbuvir for hepatitis $\mathrm{C}$ genotype 2 or 3 in patients without treatment options. N Engl J Med. 2013;368:1867-77.

12. Aptivus $^{\circledR}$ (package insert). Boehringer Ingelheim Pharmaceuticals, Inc.; Ridgefield, CT; 2014.

13. AASLD/IDSA/IAS-USA. Recommendations for testing, managing, and treating hepatitis C. http://www.hcvguidelines.org. Accessed Mar 19, 2015. 
14. Kirby B, Mathias A, Rossi S, et al. No clinically significant pharmacokinetic drug interactions between sofosbuvir (GS-7977) and HIV antiretrovirals atripla, rilpivirine, darunavir/ ritonavir, or raltegravir in healthy volunteers. 63rd Annual Meeting of the American Association of the Study of Liver Diseases (AASLD) 2012. Nov 9-11, 2012, 2013; Boston, MA. (Abstract).

15. Olysio $^{\circledR}$ (package insert). Janssen Therapeutics; Titusville NJ; 2013.

16. Izquierdo L, Helle F, François C, et al. Simeprevir for the treatment of hepatitis $\mathrm{C}$ virus infection. Pharmgenom Pers Med. 2014;7:241-9.

17. Atripla ${ }^{\circledR}$ (package insert). Gilead Sciences, Inc.; Foster City, CA; 2013.

18. Tybost $^{\circledR}$ (package insert). Gilead Sciences, Inc.; Foster City, CA; 2012.

19. Stribild ${ }^{\circledR}$ [package insert]. Gilead Sciences: Foster City, CA; August 2012.

20. University of California, San Francisco; HIV in-site website: http://hivinsite.ucsf.edu/insite?page=ar$0002 \&$ post $=6 \&$ param $=25 \&$ param $=243$. Accessed Dec 1, 2014.

21. Ouwerkerk-Mahadevan S, Sekar V, Simion A, et al. The pharmacokinetic interactions of the HCV protease inhibitor simeprevir (TMC435) with HIV antiretroviral agents in healthy volunteers. Presented at Infectious Disease Society Association; San Diego, CA Oct 17-21-2012 (Abstract).

22. Harvoni ${ }^{\circledR}$ (package insert). Gilead Sciences, Inc. Foster City, CA. October 2014.

23. Lawitz E, Poordad FF, Pang PS, et al. Sofosbuvir and ledipasvir fixed-dose combination with and without ribavirin in treatment-naive and previously treated patients with genotype 1 hepatitis $\mathrm{C}$ virus infection (LONESTAR): an openlabel, randomised, phase 2 trial. Lancet. 2014;383(9916):515-23.

24. Gane EJ, Stedman CA, Hyland RH, et al. Efficacy of nucleotide polymerase inhibitor sofosbuvir plus the NS5A inhibitor ledipasvir or the NS5B nonnucleoside inhibitor GS-9669 against HCV genotype 1 infection. Gastroenterology. 2014;146(3):736-743.e1.

25. German P, Pang PS, West S, et al. Drug interactions between direct-acting anti-HCV antivirals sofosbuvir and ledipasvir and HIV antiretrovirals [Presentation]. Paper presented at: 15th international workshop on clinical pharmacology of HIV and hepatitis therapy; May 19-21, 2014; Washington DC.
26. Victrelis ${ }^{\circledR}$ (package insert). MERCK \& CO., Inc; Whitehouse Station, NJ; 2011.

27. Hulskotte EG, Feng HP, Xuan F, et al. Pharmacokinetic interactions between the hepatitis $C$ virus protease inhibitor boceprevir and ritonavir-boosted HIV-1 protease inhibitors atazanavir, darunavir, and lopinavir. Clin Infect Dis. 2013;56(5):718-26.

28. Incivek $^{\circledR}$ (package insert). Vertex Pharmaceuticals (Canada) Incorporated; Laval, Quebec; 2013.

29. Garg V, Chandorkar G, Yang Y, et al. The effect of CYP3A inhibitors and inducers on the pharmacokinetics of telaprevir in healthy volunteers. Br J Clin Pharmacol. 2012;75:431-9.

30. Kakuda T, Leopold L, Nijs S. Pharmacokinetic interaction between etravirine or rilpivirine and telaprevir in healthy volunteers: a randomized, two-way crossover trial. 13th international workshop on clinical pharmacology of HIV therapy, Barcelona; 2012 (Abstract).

31. van Heeswijk R, Vandevoorde A, Boogaerts G, et al. Pharmacokinetic interactions between ARV agents and the investigational HCV protease inhibitor TVR in healthy volunteers. 18th conference on retroviruses and opportunistic infections, Boston; 2011 (Abstract).

32. van Heeswijk R, Garg V, Boogaerts G, Vandebosch A, et al. The pharmacokinetic interaction between telaprevir and raltegravir in healthy volunteers. 51th ICAAC meeting, Chicago; 2011 (Abstract).

33. Copegus ${ }^{\circledR}$ (package insert). Genentech, Inc; South San Francisco, CA; 2013.

34. Japour AJ, Lertora JJ, Meehan PM, et al. A phase-I study of the safety, pharmacokinetics, and antiviral activity of combination didanosine and ribavirin in patients with HIV-1 disease. J Acquir Immune Defic Syndr Hum Retrovirol. 1996;13:235-46.

35. Torriani FJ, Rodriguez-torres M, Rockstroh JK, et al. Peginterferon Alfa-2a plus ribavirin for chronic hepatitis $C$ virus infection in HIV-infected patients. N Engl J Med. 2004;351(5):438-50.

36. Foster GR. Pegylated interferon for the treatment of chronic hepatitis C: pharmacological and clinical differences between peginterferon-alpha- $2 \mathrm{a}$ and peginterferon-alpha-2b. Drugs. 2010;70(2):147-65.

37. Viekira Pak ${ }^{\mathrm{TM}}$ (package insert). AbbVie Inc.; North Chicago, IL; 2015.

38. Andreone P, Colombo M, Enejosa, JV, et al. PEARLII: randomized phase 3 trial of interferon-free, 12-week regimen of ABT-450/r/ABT-267, ABT-333 
with or without ribavirin in Hepatitis $\mathrm{C}$ virus genotype 1b-infected, treatment-experienced patients. Gastroenterology. 2104;146(5):S-159.

39. Feld JJ, Kowdley KV, Coakley E, et al. Treatment of HCV with ABT-450/r-ombitasvir and dasabuvir with ribavirin. N Engl J Med. 2014;370(17):1594-603.

40. Zeuzem S, Jacobson IM, Baykal T, et al. Treatment of HCV with ABT-450/r-ombitasvir and dasabuvir with ribavirin. N Engl J Med. 2014;370(17): 1604-16.

41. Ferenci P, Bernstein D, Lalezari J, et al. ABT-450/ r-ombitasvir and dasabuvir with or without ribavirin for HCV. N Engl J Med. 2104;370(21):1983-1992.

42. Poordad F, Hezode C, Trinh R, et al. ABT-450/ r-ombitasvir and dasabuvir with ribavirin for hepatitis $\mathrm{C}$ with cirrhosis. $\mathrm{N}$ Engl J Med. 2014;370(21):1973-82.

43. Sulkowski MS, Eron JJ, Wyles D, et al. Ombitasvir, paritaprevir co-dosed with ritonavir, dasabuvir, and ribavirin for hepatitis $\mathrm{C}$ in patients co-infected with HIV-1: a randomized trial. JAMA. 2015.

44. Eron JJ, Lalezari J, Slim J, et al. Safety and efficacy of ombitasvir-450/r and dasabuvir and ribavirin in $\mathrm{HCV} / \mathrm{HIV}-1$ co-infected patients receiving atazanavir or raltegravir ART regimens. J Int AIDS Soc. 2014;17(4 Suppl 3):19500.

45. Khatri A, Wang $\mathrm{T}$, Wang $\mathrm{H}$, et al. Drug-drug interactions of the direct-acting antiviral regimen of ABT-450/r, ombitasvir, and dasabuvir with HIV protease inhibitors. [Abstract 484] 54th interscience conference on antimicrobial agents and chemotherapy (ICAAC). Sept 5-9, 2014; Washington, DC.

46. Khatri A, Wang $\mathrm{T}$, Wang $\mathrm{H}$, et al. Drug-drug interactions of the direct-acting antiviral regimen of ABT-450/r, ombitasvir, and dasabuvir with emtricitabine + tenofovir, raltegravir, rilpivirine and efavirenz. [Abstract 438] 54th Interscience Conference on Antimicrobial Agents and Chemotherapy (ICAAC). Sept 5-9, 2014; Washington, DC. 